\title{
O problema do conhecimento verdadeiro na epidemiologia
}

\section{The problem of true knowledge in epidemiology}

\author{
José Ricardo de Carvalho Mesquita Ayres*
}

\begin{abstract}
AYRES, J.R. de C.M. O problema do conhecimento verdadeiro na epidemiologia. Rev. Saúde públ., S. Paulo, 26: 206-14, 1992. São examinadas as bases filosóficas da validação do conhecimento cientifico, com o intuito de estabelecer uma visão crítica a respeito da adoção das proposições de Popper na epidemiologia. Ressalta-se o caráter conservador que resulta das limitaçōes técnicas implicadas na sua adoção, não obstante o evidente aumento da racionalidade e da criatividade heurística que propicia.
\end{abstract}

Descritores: Métodos epidemiológicos. Filosofia. Medicina social.

No curso de seu desenvolvimento científico, a epidemiologia vem se defrontando com uma série de questōes de natureza filosófica que, sem serem apanágio seu, assumem características decisivas no âmbito de suas práticas. Trata-se do fato de que ao se propor a produzir um conhecimento que aspira à condição de verdade objetiva, a epidemiologia precisa não só posicionar-se frente o problema da natureza e das possibilidades do seu conhecimento, o que de resto precisará fazer toda ciência, mesmo que o desconheça ou negue, como também, e daí o caráter crucial assumido por estas questões, deverá buscar sua identidade enquanto ciência neste efetivo posicionamento.

Pode parecer estranho que um conhecimento de natureza cientifica tenha sua identidade, isto é, as características pelas quais se distingue como campo específico de produçāo de conhecimento, relacionada com questōes que, à primeira aproximação, podem parecer dizer respeito a esferas extracientíficas. De fato, as concepçōes mais difundidas e legitimadas acerca da ciência têm por base a idéia de que existe uma forma necessária e suficiente de produzir conhecimentos capazes de expressar as verdades objetivas do mundo, e que, portanto, os questionamentos filosóficos da ciência relacionar-se-ão antes com os problemas de sua efetividade do que com os de sua identidade. Estes últimos são normalmente remetidos à esfera do objeto da ciência, nos diversos planos de sua construção,

\footnotetext{
* Centro de Saúde Samuel B. Pessoa, Departamento de Medicina Preventiva da Faculdade de Medicina da Universidade de Săo Paulo - Săo Paulo, SP - Brasil.

Separatas/Reprints: J.R. de C.M. Ayres - Av. Dr. Amaldo, 455 - 01246 -903 - São Paulo, SP - Brasil.

Publicação financiada pela FAPESP. Processo Saúde Coletiva 91/4994-0.
}

enquanto os primeiros são remetidos à esfera exclusiva dos sujeitos e seus valores.

Ocorre que esta forma de tomar a identidade de uma ciência como uma questão relativa apenas ao seu objeto, nega, em sua positividade, o movimento inverso ocorrido no plano da prática científica concreta, em que o objeto de uma ciência, na sua dimensão de construção teórica, é também produto do olhar que se detém sobre o real em busca de suas verdades ocultas. Em outras palavras, a atribuição de uma natureza predominante funcional aos questionamentos acerca das relaçöes entre o ser e a consciência, isto é, entre a existência objetiva e sua apreensão racional, deve-se à negação da pluralidade contraditória da objetividade, em que os objetos admitem objetivaçōes conceituais diversas nos limites de sua objetividade real.

O proposital jogo de palavras acima não deve ser tomado como um exercício retórico vazio de conteúdos. Ao contrário, buscou-se lançar mão de um artifício enfático para apontar aquele que será o fio condutor desta reflexão. Este, se não é a única forma de aproximação a uma das questōes de maior relevância para as perspectivas do desenvolvimento científico da epidemiologia, a de sua identidade, parece ser uma das mais profícuas formas de apreender seu eixo nuclear de determinação: a dialética da construção de um objeto teórico.

Assim é que, do ponto de vista adotado nesta reflexão, não passa de uma unilateralização deformadora concebermos que a identidade de uma ciência resida exclusivamente nos aspectos intrínsecos à objetividade, quer em relaçảo àqueles eminentemente racionais, às suas mediaçōes conceituais, quer se trate daqueles relativos às características concretas do objeto. 
Admitir que a natureza de um conhecimento e suas possibilidades cognitivas diante do imediato dado se refiram apenas ao interesse prático e viabilidade técnica de uma ciência é, como contrapartida dessa unilaterização da apreensão do movimento real da práxis científica, olvidar a determinaçäo social que se encontra na origem da constituição de um ramo qualquer do conhecimento cientifico. Estas determinações sociais, longe de serem relevantes apenas no âmbito de dimensões extrínsecas à estrutura interna de uma ciência (como quer a epistemologia nos seus moldes mais clássicos), como os aspectos historiográficos, axiológicos e éticos de uma prática científica, estão radicalmente relacionadas com a própria gênese de uma ciência na forma específica como se configura técnico-metodologicamente.

De fato, a história da ciência está repleta de exemplos de como se produziram mudanças qualitativas radicais no âmago da apreensāo positiva de verdades objetivas a partir de transformações ocorridas externamente aos planos estritamente técnico-metodológico do pensamento cientifico. Por outro lado certas transformações técnicas operadas nas ciências modificam de tal forma a relação destas com o real concreto que se opera quase uma metamorfose nas feições pelas quais certo aspecto do real nos é dado a conhecer.

Ora, se o que foi afirmado acima é verdadeiro, será razoável concluir que só será possível atribuir a identidade de uma ciência à esfera exclusivamente relativa ao seu objeto se lançarmos mão de uma concepção apriorística de ciência que reduza seus elementos não científicos a adjetivadores fortuitos. Só um saber que concebe a si próprio como portador absoluto da objetividade do real pode supor que as diferentes qualidades que especificam seus diferentes ramos não digam respeito às características internas da apropriação cognitiva que faz do real.

É preciso que fique claro, que não se quer negar a primazia do objeto real na determinação da gênese das ramificações da ciência, se é que se pode falar de ramos de uma única ciência. $O$ ponto a que se deseja chegar é que a racionalidade consubstancial com a ciência em sua configuração moderna, ao se voltar reflexivamente sobre suas bases teórico-metodológicas, traduz uma dicotomia entre método e objeto na legitimação do saber verdadeiro que detrai as determinaçōes que os articulam dialeticamente no real concreto. Ou seja, por trás da absolutização da perspectiva cognoscente pela qual se legitimou a ciência moderna nos seus mais de três séculos de existência, há uma postura filosófica especifica diante do ser e da consciência, a qual conduz à separação artificial entre a indagação sobre o que seja uma ciência e sobre como esta deve proceder. Ao negar o conteúdo metodologicamente impresso no objeto do conhecimento, uma tal reflexão não permite que se perceba que o critério pelo qual se define o que é verdadeiro determina, em parte, o conteúdo efetivamente apreendido das verdades; não deixa ver que a heurística de uma ciência é indissociável do que será seu conteúdo teórico específico.

Justifica-se, entäo, a importância que assume na atualidade o problema da verdade na epidemiologia, já que nesta, além das motivaçōes oriundas das finalidades pelas quais se legitima qualquer proposição científica, o debate acerca da identidade como campo específico da ciência dá à reflexão sobre a natureza e as possibilidades do conhecimento verdadeiro um caráter ontológico. Em outras palavras, no caso particular da epidemiologia, discutir as relaçōes entre o ser e a consciência confunde-se com discutir qual é o específico campo de aplicação da epidemiologia e quais as suas articulações sociais enquanto campo de saber, o que para outras ciências, especialmente as chamadas ciências naturais $e$ as ciências exatas, não se coloca como questão, ao menos com o caráter de urgência que se coloca na epidemiologia.

Por que terá, contudo, assumido tamanha importância o problema da verdade na epidemiologia, a ponto de colocar-se em questão, nessa discussão, sua própria identidade? De onde advém a gravidade da absolutização, na racionalidade científica moderna, de uma determinada postura epistemológica para a caracterização da epidemiologia enquanto campo de saber?

Parece impossível responder a estas perguntas sem se ocupar, ainda que superficialmente, das já apontadas bases filosóficas da racionalidade científica moderna confrontando-as com as questões concretas do desenvolvimento da epidemiologia. Só este circunstanciamento histórico da ciência epidemiológica e de seus pressupostos teóricos poderá nos levar à transcendência de suas aparências imediatas, sem cair nas soluções tautológicas da interpretação lógico-formal da configuração concreta da mesma. Trata-se, portanto, de levar a razão à superação de sua transcendência supostamente natural, na direção da objetividade social, da qual a razão se afasta, continuadamente, pelo movimento próprio à dinâmica objetiva de sua socialidade. $O$ processo racional auto-reflexivo que se quer aqui desenvolver começa, assim, pela busca das determi- 
nações da alienação mesma da racionalidade científica de sua própria objetividade.

Whitehead ${ }^{7}$ define a revolução científica da racionalidade moderna como uma reação irtacionalista às teorias medievais sobre o ser e a consciência, irrompida na Europa no século XVII. A aparente incoerência de uma formulação teórica que define o nascimento do primado da razão por sua próptia irracionalidade pode suscitar estranheza numa primeira leitura. Ela remete, contudo, à essência das bases filosóficas da ciência moderna. É a este mesmo movimento irracionalista da razão que se refere também a Escola de Frankfurt, ao apontar a "regressão racional burguesa", expressa no conceito de razão instrumental, e mesmo Popper, a partir do seu racionalismo crítico.

Não deixa de ser curioso que seja preciso qualificar um racionalismo por sua natureza crítica, já que custa imaginar um racionalismo que não tenha por base alguma espécie de crítica. Mas deixando de lado, por enquanto, este aspecto, volte-se à definição de Whitehead.

Extrapola os limites desta reflexão fazer uma recuperação exaustiva das condiçōes materiais das quais promanou o movimento de transformação de que se está ocupando no plano abstrato das idéias. É fartamente conhecida a bibliografia que fundamenta teoricamente as relaçōes concretas entre o irrompimento da racionalidade cientifica moderna e a emergência do modo de produção capitalista. Interessarão apenas certas dimensōes dessas articulaçōes que parecem suficientes para os propósitos desta reflexão.

Inicie-se por tomar aquela que interessa de imediato: a profunda secularização que passa a permear todas as relaçōes sociais na nova ordem. De fato, a aparência transcendental de que se revestia a organização social da produção e, correlatamente, a natureza divina da ordem social no regime feudal, não encontra cortespondência num modo de produção que se baseia na liberação mercantil da força de trabalho e na livre circulação e consumo dos objetos de uso. Neste modo de produção, a divisão social do trabalho e da riqueza precisa apoiar no homem e nas suas virtuais capacidades e necessidades a origem e os ideais de uma sociedade humana justa e adequada.

Diz-nos Koyré ${ }^{4}$ que as concepções do mundo são como um caleidoscópio em que se combinam diversos tipos de contas, agrupadas em três espécies principais que se interelacionam: Deus, Natureza e Homem. Utilizando-nos desta imagem, pode-se dizer que na emergência da ordem capitalista move-se o caleidoscópio. A na- tureza surge não mais como decorrência das necessidades do homem, na sua odisséia de "contínua realização de Deus na terra", mas como a obra autônoma, por cuja compreensão e domínio pode o homem alcançar a transcendência de sua existência. Esta naturalização, inicialmente ainda divinizada e posteriormente definitivamente secularizada, é que torna possível a referida reação irracionalista à racionalidade escolástica medieval na formulação teórica das verdades objetivas do mundo.

No plano autonomizado das injunçōes materiais, o movimento racional da apreensão das mesmas não pode ser compreendido senão como algo de natureza distinta das coisas mesmas. A menos que houvesse uma ruptura súbita e radical com o caráter transcendente da natureza humana, não se poderia conceber a unidade entre ser e consciência, que caracterizava o aristotelismo escolástico, sem ter que assumir a imanência divina do status quo. À revolução social que superou o regime feudal correspondeu, então, uma revolução fillosófica acerca do problema da verdade objetiva que, baseada na concepção do mundo como uma ordem natural, contesta os arraigados conceitos racionais qualitativistas como explicação da objetividade do real.

Apesar da óbvia derivação do aristotelismo, de onde herdou o caráter metódico e a concepção legalista do real, a racionalidade científica moderna realiza um evidente retorno ao quantitativismo platônico e neopitagórico da baixa idade média como recurso para superar a tão delicada questão da qualidade dos objetos do real. As quantidades são capazes de explicar as diferenças e as especificidades das leis naturais, independente de suas qualidades transcendentais para o homem.

O caráter urgente e dramático de todas as revoluçōes fez com que essa natureza puramente relacional entre os diversos aspectos do real, e entre este e o seu conhecimento, fosse levada às últimas conseqüências no movimento que, segundo Whitehead, reduz a possibilidade do conhecimento verdadeiro à abstração das caracteristicas matemáticas que relacionam os fatos inexoráveis e irredutíveis, que tem nas idéias de Hume sua mais radical defesa. Este criticava drasticamente qualquer tipo de abstração generalizante de ordem metafísica, fosse a partir do racionalismo ou fosse baseado numa indução matemático-empírica.

Burtt ${ }^{3}$ também aponta esta redução do conhecimento objetivo à apreensão da combinação das quantidades simples de que se compõe o mundo material, baseando a cosmologia da ciên- 
cia moderna na legalidade mecânico-matemática.

É verdade que o final do século XVIII e inicio do século XIX assistem a uma reação do racionalismo, expresso por um lado na síntese do ímpeto classificatório - já artaigado na metodologia científica - em termos de uma qualidade orgânica, e por outro lado, no idealismo filosófico que busca resgatar na transcendência do conhecimento humano uma metafísica de base ética, que tem em Kant seu principal expoente. Essa experiência não modifícou radicalmente, contudo, a tendência essencial da racionalidade científica moderna. Sua espantosa eficácia tecnológica e profunda articulação ideológica às condições históricas concretas da reprodução da sociedade capitalista lograram reproduzi-la hegemonicamente.

$\mathrm{Na}$ realidade a radicalização irtacionalista e a reação racionalista, acima apơntádas, são apenas momentos críticos de um diálogo que é constantemente travado entre-racionalismo e empirismo ao longo da história do conhecimento humano. Obviamente não interessará aqui uma discussão minuciosa dos diversos momentos desse diálogo antitético e das sínteses nas quais se configuraram, concretamente, sua superação, nos diversos momentos de sua histótia. Interessa reter o que permanece como denominador comum a ambas as equações do problema do conhecimento verdadeiro, tanto em seu polo racionalista como em seu polo empiricista, porquanto aí está a chave da compreensão da relação entre critério objetivo de verdade e identidade científica na epidemiologia. Trata-se do agnosticismo que caracteriza estruturalmente a racionalidade científica moderna, e que decorre de sua própria revolução.

De fato, após ter deslocado Deus e todas as razões divinas da explicação da realicade objetiva, a racionalidade moderna tem de se confrontar com um novo e inevitável adversário: a sua própria irracionalidade. Enquanto prevalecia a concepção imanentista do conhecimento humano, o problema da relação entre a existência e sua apropriação cognitiva residia antes no questionamento filosófico da própria existência que no ato de conhecimento em si. Conhecer era próprio do homem como cair era próprio aos corpos de matéria densa. O sentido do conhecimento era o sentido da própria existência do homem em sua transcendência divino-genérica. Quando, no entanto, o homem perde essa natureza divina e passa a tomar-se enquanto gênero a partir de sua transcendência racional, emerge a possibilidade da argüiçāo ontológica acerca não só da existência objetiva como também do conhecimento objetivo. Deserdado de sua linhagem divina, o homem já não tem garantias acerca da natureza do seu conhecimento, da fidedignidade das fontes do mesmo e de seu efetivo alcance explicativo.

Diante das possibilidades que então se abriam para a emancipação da razão humana e dentro do contexto sócio-político concreto em que tais possibilidades se abriram, a racionalidade científica passa de seu papel revolucionário, ao liberar o gênero humano do determinismo fechado de uma cosmogonia religiosa, para o papel conservador de uma racionalidade fechada numa ontologia baseada em conexões lógicas empiricamente abstraídas. Estamos no século XIX, referimo-nos à doutrina filosófica positivista. A classe burguesa que estivera à frente dos movimentos revolucionários que depuseram o Antigo Regime consolida-se no poder e se entrincheira em todas as suas instâncias para garantir a hegemonia do seu projeto de sociedade.

Enquanto uma das importantes "trincheiras" da nova ordem social, a filosofia científica se vê na delicada tarefa de conter o curso histórico que, havia pouco tempo, ajudara a acelerar. Viuse diante da contradiçāo de estar consolidando uma racionalidade cujo caráter aberto apontava para a sua própria superação. $O$ positivismo e sua negatividade filosófica da contradição - sendo, nesse sentido, uma doutrina quase "nāo filosófica", já que não há espaço para fílosofia onde só cabem certezas - corresponde, no plano das idéias, à reação burguesa às proposiçōes políticas de reformas sociais mais radicais, que emergiram neste periodo histórico. A indeterminação de conteúdo, o procedimento ordenador e a preferência pela certeza são, segundo Adorno', as bases sobre as quais o positivismo, e sua postura epistemológica "anistoricizante" do real e "desontologizante" do conhecimento, erige sobre uma nova e inaparente metafísica a razão científica.

Apesar de suas recentes transformações ténicas e epistemológicas, a ciência moderna e sua racionalidade parecem manter inalteradas suas estruturações nucleares: o indutivismo e sua finalização teórica positivista seguiram sendo a forma hegemonicamente legitimada de produção de conhecimentos verdadeiros. Quer parecer que mesmo a relativização da objetividade, a proposição da possibilidade de uma coexistência compativel de diferentes modelos explicativos de um mesmo campo de fenômenos e o grau altamente abstrato das categorias conceituais da ciência contemporânea, especialmente das ciên- 
cias físicas e matemáticas, não chegaram a modificar substancialmente o agnosticismo da racionalidade cientifica hegemônica. É claro que na atualidade este agnosticismo está muito distante do realismo materialista que esteve em sua origem, e o primado do método na definição do conteúdo de verdade de um saber atesta-o perfeitamente. Toda a novidade epistemológica da ciência contemporânea é remetida para uma filosofia metacientífica, deixando inalterado o conteúdo filosófico inexoravelmente inscrito no momento propriamente heurístico da prática científica.

A aparente abstençāo de um posicionamento efetivamente crítico diante da apreensão da verdade objetiva por parte do seu sujeito - apenas aparente pois, como se viu ele existe e é socialmente determinado - é, em síntese, uma generalizaçāo de natureza superlativa de uma determinada relação método-objeto, de uma área específica do conhecimento humano, as ciências naturais, para o conjunto da prática científica.

A partir da hegemonia historicamente observada da perspectiva cognoscente acima descrita, os questionamentos anteriormente formulados acerca da importância do problema da verdade para as perspectivas futuras da ciência epidemiológica assumem maior clareza. Se a negação da determinação não racional da racionalidade científica é já problemática no âmbito de suas próprias matrizes, as ciências naturais (onde a autonomia acentuada dos objetos por referência à perspectiva de sua apreensão cognitiva tende a minimizar a influência do sujeito na objetividade apreendida), o que dizer de saberes que, como a epidemiologia, se ocupam de práticas ou condições relativas ao homem em sua socialidade. No primeiro caso sempre haverá o risco, como nos adverte Adomo', de que se produza uma paralização do desenvolvimento do conhecimento, posto que "o fato dos positivistas, num gigantesco círculo, extrapolarem da ciência as regras que deverão fundamentá-la e justificá-la possui conseqüências fatais também para a ciência, cujo progresso efetivo inclui tipos de experiência que por sua vez não são prescritos e aprovados pela ciência". No segundo caso o cientificismo tem conseqüências ainda mais graves, posto que a própria possibilidade de apreensão do real fica comprometida pela negação da subjetividade.

Assim, a dicotomia epistemológica entre objeto e método, resultante do afã de desqualificar os valores humanos, a crítica, como legítima orientação da apropriação cognitiva do real, se é problemática na ciência de uma forma ge- ral, na ciência que se ocupa da sociedade ou do homem em sua dimensão humanistica ela se torna insustentável. Um conhecimento humanistico produzido nestes moldes só poderá legitimar-se como conhecimento verdadeiro ou a partir da objetivação de aspectos muito genéricos de seu objeto, de valor prático muitas vezes restrito demais, ou se ocupando de aspectos parcelares do real, restringindo-se a relaçōes funcionais de escasso valor explicativo do movimento de suas próprias gêneses.

No contexto histórico privilegiado das ciências humanas ganham entāo maior vitalidade as proposições críticas acerca do cientificismo na produção do conhecimento verdadeiro, especialmente nas ciências sociais. Se se considerar, portanto, que a epidemiologia, em função das caracteristicas concretas de seu objeto, determina-se como uma ciência do social, já que este é - campo de determinações objetivas no qual esta se dispōe a apreender os fenômenos da saúde e da doença, poderemos responder à pergunta que nos faziamos anteriormente acerca do motivo do caráter problemático da absolutizaçāo cientificista do conhecimento verdadeiro em epidemiologia. Ele se refere, já em primeiro lugar, à inadequação do "ponto de vista arquimediano" da ciência moderna como perspectiva cognoscente da objetividade do social.

Note-se que a essência do problema acima é predominantemente referente à esfera do que chamamos, no início deste texto, de efetividade da ciência, isto é, ele é relativo à esfera da eficácia técnica da ciência e da legitimação social da mesma. É somente no âmbito restrito, embora de maneira alguma desimportante, desta efetividade que se enxergam as possibilidades concretas de repercussão, na epidemiologia, das proposições metodológicas de inspiração popperiana, ou as neopositivistas, de uma forma geral. Isto acontece justamente porque tais proposições, inclusive o racionalismo crítico de Popper, deixam intocado o fundamento agnóstico no núcleo do processo heurístico.

Não setão tratadas as proposições metodológicas lógico-matemáticas recentes na ciência epidemiológica, porque, embora tais proposiçōes já sejam derivações distintas do método epidemiológico clássico, baseado nos cânọnes positivistas de J.S. Mill, elas não se diferchiciam o suficiente, em qualidade e profundidade, dos pressupostos científicos clássicos, que foram discutidos. A proposição racional-dedutivista de Popper assume maior interesse para a prisente reflexāo, tanto pelo que traz de novidade, em termos metodológicos, como pela sua importância 
na filosofia da ciência em geral.

O que nos diz Popper, então, acerca do conhecimento verdadeiro?

O desenvolvimento da filosofia popperiana acerca do conhecimento desenvolveu-se basicamente a partir da crítica ao primado da experiência na definição do saber científico. Neste sentido, sua crítica visa dois alvos principais, constitutivos, embora, de um mesmo movimento: a experiência sensível como fonte exclusiva do conhecimento e o indutivismo como processo totalizador do conhecimento, como tradução da legalidade do real. Opōe-se, dessa forma, a toda concepção naturalista da verdade e do seu conhecimento, e afirma a indissociabilidade de sujeito e objeto no processo de conhecimento.

O objeto do conhecimento é para Popper ${ }^{6}$ uma construção, é um objeto objetivado, por oposição a um objeto puramente natural. No objeto do conhecimento (o objeto objetivado) misturam-se as determinações objetivas próprias ao real e aquelas oriundas do sujeito do conhecimento, seus valores, suas motivações, suas coerções sociais. Estas últimas, por intermédio do método, determinam primordialmente a natureza última do objeto, porquanto o método é o instrumento de objetivação, por excelência.

Como, entāo, separar os valores subjetivos do cientista daqueles provenientes das condiçōes objetivas do real? Como, em suma, separar os valores científicos dos nãos científicos? Esta é a forma como Popper problematiza a nảo externalidade do sujeito em relação ao objeto no conhecimento, na forma tal qual a apreende (e que se tornou um dos pontos fundamentais da polêmica que travou com Adorno a propósito da metodologia das ciências sociais).

Popper ${ }^{6}$ afirma que qualquer hipótese teórica é uma conjectura, e, enquanto tal, é fruto de juizos de valor, de origem científica e de origem nāo científica, surgidos do tensionamento da razão entre o conhecido e o desconhecido diante de algum problema específico - derivado sempre de alguma necessidade concreta.

Chega-se, então, à principal divergência de Popper em relação ao indutivismo. Para o filósofo vienense $o$ movimento de confirmação de uma hipótese teórica e, a partir de sua positividade, a extrapolação de leis gerais com base no comportamento do particular é um salto absolutamente metafísico, insustentavelmente irracional. A solução que propõe inverte o sentido do movimento totalizador da verdade: assume-se às últimas conseqüências a razão humana como fonte do conhecimento e, ao mesmo tempo, sua impossibiliade estrutural de conhecer a essência genética do real. A verdade será, assim, o primeiro passo da construção racional do conhecimento, será a conjectura. Caberá à ciência proceder à separação dos conteúdos objetivos dos subjetivos, alojados ambos na razão. Já que, segundo Popper , não há melhor argumento a favor de uma proposiçāo do que a inexistência de argumentos contra tal proposição, o movimento da confirmação positiva pela ciência de uma determinada conjectura será a deduçāo a partir da mesma, de problemas que possam por à prova os fundamentos teóricos dessa conjectura.

A refutabilidade será, portanto, o critério de demarcaçảo do conhecimento científico; o irrefutável remete a outras naturezas de conhecimento. $O$ irrefutado confirma a conjectura, a teoria; o refutado a obriga a reformulaçōes, inaugura novos tensionamentos entre o conhecido e o desconhecido. A verdade não tem, no conhecimento, qualquer tipo de estatuto ontológico, ela é, isto sim, uma idéia reguladora. São esses, em linhas gerais, os traços fundamentais da filosofia de Popper acerca da relação entre a existência e seu conhecimento racional objetivo.

Ora, detendo-se com atenção nos fundamentos da doutrina do "dedutivismo-refutabilidade", veja-se se nāo serão encontrados aí todos os três elementos estruturais nucleares da doutrina positivista, conforme apontado por Adomo: indeterminação de conteúdo (primado do método), procedimento ordenador e preferência pela certeza (ainda que pela sua negatividade).

Parece bastante evidente que embora a filosofia de Popper avance em relação ao indutivismo, em termos do circunstanciamento metacientífico da ciência, recuperando, no reiterado diálogo entre empirismo e racionalismo, a importância axiológica deste último, permanece intocado o agnosticismo a respeito da cognoscibilidade do real, com todas as suas já discutidas repercussōes.

Nesse sentido estrito, a filosofia de Popper tem o inegável mérito de expandir a presença do homem enquanto sujeito ativo no conhecimento, realizando uma "integração filosófica" do conhecimento parcelar oriundo da ciência, que dá respostas efetivas a parte das necessidades sentidas pela epidemiologia no curso de seu desenvolvimento científico. A este repeito, Buck ${ }^{2}$ aponta três niveis de problemas nos quais - referencial popperiano pode trazer ajuda: na orientação de quais dados colher, evitando a tendência ao desperdício a que o virtual apriorismo da observação empírica no indutivismo costuma levar; na interpretacão das relaçōes estatísticas, 
retirando dos achados matemáticos, em si mesmos, a ênfase na orientação de desenhos de pesquisa ou consideração de resultados e, finalmente, a expansão do horizonte de criatividade heurística, ao partir da conjectura para o empírico.

Rearfirme-se, contudo, a idéia de que nāo se alterará o caráter conservador da produçāo de conhecimento, não se restituirá ao homem o papel de sujeito real desse conhecimento, enquanto não se superar as contradições entre racional e irracional na intimidade do saber, e entre empirismo e racionalismo na construção do objeto. Assim, a adoção de um referencial teórico que ignora a dialética desses polos contraditórios traz o inexorável risco, muito especialmente se se tratar de uma ciência do social, de comprometer a própria efetividade que se buscava em tal adoção.

Diz-se que a negação da contradição pode comprometer inclusive a efetividade de uma ciência porque, com tal negação, assume-se tacitamente a redução do real à dimensão positivamente traduzida num dado conhecimento. Assim, se o método, que permite e determina que esta específica dimensão seja abstraída do concreto, for aplicado a aspectos do real dos quais tal abstração pouco ou nada tem a dizer de relevante, o conhecimento produzido terá comprometida sua aplicação prática. $O$ método, reiterando sempre sua própria cosmologia, acaba por sobrepor-se, com seus "caprichos", à vontade humana na decisão do conteúdo do conhecimento objetivo do mundo. Se não se identifica $e$ incorpora ao processo de conhecimento os aspectos em função dos quais a positividade é negação, poderá inviabilizar-se o projeto que o justifica enquanto necessidade de conhecer; então a razão do método suprimirá a do homem na objetivação do real.

Não é exatamente isto que acontece na aplicação de métodos quantitativo-indutivistas nas ciências sociais? Acaso tais métodos têm alcançado, nas ciências sociais, o objetivo de realizar homogeneamente os diferentes projetos humanos que as justificam? Tem, a aplicação de tais métodos às ciências humanas, obtido o mesmo sucesso revolucionário que obteve no projeto emancipador de afirmaçāo e intervenção na dimensão natural da determinação da existência?

Posta esta crítica à exclusão, no problema do conhecimento verdadeiro na esfera técnicometodológica, da dimensão histórico-ontológica do homem e seus valores; assumida a concepção de que só o resgate das contradições do real permite ao homem, através do posicionamento critico diante de tais contradiçōes, segundo seus valores, imprimir ao processo de apreensão da objetividade do real o direcionamento do conhecimento no sentido da realizaçāo destes valores; e, finalmente, entendida a inexorabilidade da presença do método no conteúdo de objetividade de uma dada apreensão racional do real concreto, está-se em condição de explicar também a importância dessas questões filosóficas no que se refere à identidade da epidemiologia.

Para que se possa compreender o porque da importância da identificação da relação serconsciência no âmago dó método para o amadurecimento da epidemiologia enquanto um campo especifico do conhecimento humano, é preciso que se coteje a crítica acima com a situação histórica concreta da epidemiologia no conjunto das práticas de saúde, caracterizada, em linhas gerais, por uma complementaridade subordinada, enquanto saber, às disciplinas científicas sobre saúde e doença de base anátomo-físio-patológica. Esses saberes, agrupados analiticamente sob a designação genérica de clínica, têm sido o determinante hegemônico das formas como concretamente se têm apreendido objetivamente o processo saúde-doença da perspectiva científica. A esse respeito afirma Mendes Gonçalves: "....a polarização analiticamente realizada entre a epidemiologia e a clínica não se realiza como oposição de qualidades radicalmente incongruentes, mas como diversidade de uma unidade básica cujo movimento tende menos para o primado de uma sobre a outra do que para a superação de ambas, enquanto estruturas de conhecimento e prática historicamente determinadas como complementares. Retenha-se contudo a evidência histórica, válida para a contemporaneidade, de que nessa relação de complementaridade é ainda o saber clínico que dá os parâmetros básicos para a estruturação o conjunto".

A questão desta complementaridade se torna, contudo, problemática quando se considera a evidência, também histórica, de que a forma como as contradiçōes da complementaridade entre o saber epidemiológico e o saber clínico se resolvem no plano da prática, resultam em uma síntese muitas vezes antitética a alguns dos importantes pressupostos que fundamentam o projeto de uma ciência epidemiológica.

Enquanto ciência aplicada, a epidemiologia, na complexidade de dimensões objetivas de que precisa dar conta para apreender a determinação de seu objeto, tem se constituído como uma disciplina limítrofe entre diversas áreas do conhecimento humano. É inegável a contribuição que as ciências socias têm trazido ì estruturação desta disciplina, e é exatamente desta contribui- 
ção que advém o caráter às vezes contraditório das premissas e conclusōes na produção do conhecimento epidemiológico.

Uma vez que 0 objeto conceitualmente construído por uma ciência resulta da objetividade tanto do objeto quanto do sujeito do conhecimento, e que, portanto, o método do conhecimento determinará em parte o conteúdo da objetividade apreendida, o convívio de perspectivas cognoscentes diversas na epidemiologia colocará em xeque sua identidade.

Não fazendo parte dos objetivos desta reflexão discutir os determinantes e as soluções destas antíteses e suas repercussões concretas, interessa apenas reter o fato de que a opção metodológica será indissociável da síntese concreta das contradições com que a epidemiologia terá que conviver na sua condição de disciplina científica de interface entre outras disciplinas científicas, de natureza muita diversa entre si. Assim, o que está em jogo quando se discute o problema da verdade na ciência epidemiológica é muito mais que uma discussão técnico-metodológica, mas uma profunda crítica teórico-metodológica. A reflexão sobre a relação da existência dos fenômenos da saúde e da doença com as formas de sua apreensão racional não deixará incólume sequer a complementaridade subordinada da epidemiologia em relação à clínica, diante da qual o sujeito de uma tal reflexão terá que posicionar-se, necessariamente. Criticar o instrumental técnico-metodológico que a epidemiologia vem utilizando predominantemente é criticar a teoria sobre saúde e doença que este efetivamente abstrai do real, não para negá-la ou afirmá-la de modo absoluto e integral, mas superá-la em formas adequadas aos projetos que geram as questões para o conhecimento.

É neste sentido que parecem ser inadequadas as proposiçōes, quanto a esta questão, de soluções que, inscrevendo-se no mesmo referencial teórico que criticam, não fazem outra coisa senão reiterar concepçōes que, não raro, estão na base dos problemas que se quer resolvidos com tais preposiçōes. É assim que se entende a aplicação da filosofia de Popper ${ }^{6}$ à epidemiologia, se sua pretensão for maior do que aquelas às quais se referiu Buck, fique claro.

A epidemiologia nāo poderá autonomizar-se enquanto um campo específico do conhecimento sobre saúde e doença enquanto não dispuser de instrumental teórico-metodológico que a aproxime crescentemente da abstração conceitual da gênese essencialmente social do processo saúdedoença. Enquanto a abstraçāo que legitima suas teorias se restringir à dimensão exclusiva, estéril para um objeto de natureza social, das leis gerais do comportamento dos fenômenos "inexoráveis 'e irredutíveis" da saúde e da doença-exprimíveis lógico-matematicamente - a epidemiologia seguirá sendo o "braço da clínica" sobre as esferas extrabiológicas do processo saúdedoença.

Embora já não sejam poucas as contribuições que este caráter instrumental da epidemiologia vem trazendo à compreensão e intervenção sobre o processo saúde-doença, não há razôes, senão de natureza ideológica, para que a ciência epidemiológica se restrinja a elas. A situação de interface entre diversos ramos do saber se, de um lado, traz as dificuldades técnico-metodológicas acima apontadas, traz também, de outro lado, a possibilidade muito rica de uma transdisciplinaridade cuja sintese pode revelar, objetivamente, importantes determinaçōes ontogenéticas. Contudo, só uma atividade explícita e resolutamente ativa neste sentido poderá alcançar e legitimar esta síntese. A ideologia científica de um saber médico-social e as evidências já apontadas, às vezes até fortuitamente, da substância social da distribuição dos fenômenos da saúde e da doença na coletividade só poderão legitimarse socialmente como conhecimento verdadeiro se forem traduzidas, em sua contraditoriedade histórica, como verdade objetiva.

É preciso que se supere, portanto, a indeterminaçāo positivista do conteúdo inscrito no método cientifico e que se transforme esta "vontade" de uma epidemiologia "Social" em processos determinados de apreensão da objetividade da gênese social da saúde e da doença, na totalidade objetiva que explica tanto esta vontade de conhecer quanto o que se quer conhecido.

Se não serve, para isso, a metafísica matemático-indutivista, tampouco o servirá uma totalidade conjectural, como a proposta por Popper $^{6}$, e a natureza quimeristica da verdade que produz. Se no primeiro caso há um ceticismo em relação à transcendência genérica da razão humana quanto à possibilidade do conhecimento verdadeiro, incompativel com a presença desta razão no próprio objeto a ser conhecido, há no agnosticismo de moldes popperianos uma desconfiança em relação à natureza objetiva do valor que é insustentável num conhecimento que não se quer restringir à eficácia instrumental na resolução de problemas cuja origem desconsidera.

A construção de uma epidemiologia que concorra efetivamente para a emancipação do humano-genérico, na sua dimensão histórico-ontológica, o desenvolvimento de um conhecimento que não escamoteie as contradiçōes entre 
ciência e história (uma nova ciência? uma nãociência?) precisará, segundo Adomo', superar o "sempre que...então" pela proposição dialética do "dado que...é preciso". O epidemiólogo precisa assumir sua responsabilidade política na "objetividade cujo conhecimento persegue" - o processo saúde-doença enquanto processo substantivamente social - já que "o conhecimento é nesta força produtiva e tanto mais quanto maior é o progressso da ciência".

AYRES, J.R. de C.M. [The problem of true knowledge in epidemiology]. Rev. Saúde públ., S. Paulo, 26: 206-14, 1992. The philosophical basis of the validation of scientific knowledge, with a view to stablishing a critical point of view as to the adoption of Popper's propositions in epidemiology is examined. The conservative character that results from the technical limitations implied in this adoption is a noteworthy aspect of the discussion, despite the evident increase in heuristic rationality and creativity that result.

Keywords: Epidemiologic methods. Philosophy. Social medicine.

\section{Referências Bibliográficas}

1. ADORNO, T.W. Introdución. In: Adomo, T.W. et al La disputa del positivismo en la sociologia alemana. Barcelona, Ediciones Grijalbo, 1973. p. 11-80.

2. BUCK, C. Popper's philosophy for epidemiologists. Int. J. Epidem., 4: 159-68, 1975.

3. BURTT, E.A. As bases metafísicas da ciência moderna. Brasilia, Ed. Universidade de Brasilia, 1983.

4. KOYRE, A. Do mundo fechado ao universo infinito. Rio de Janeiro, Ed. Forense-Universitária, 1986.

5. MENDES GONÇALVES, R.B. Tecnologia e organização social das práticas de saúde: características tecnológicas do processo de trabalho na rede estadual de centros de saúde de São Paulo. São Paulo, 1986. [Tese de Doutorado - Departamento de Medicina Preventiva da Faculdade de Medicina da USP].

6. POPPER, K.R. A lógica das ciências sociais. In: Popper, K.R. Em busca de um mundo melhor. Lisboa, Ed. Fragmentos, 1989. p. 71-85.

7. WHITEHEAD, A.N. A ciéncia e o mundo maderno. São Paulo, Ed. Brasiliense, 1952.

Recebido para publicaçāo em 11/6/1991 Reapresentado em 11/11/1991 Aprovado para publicação em 10/2/1992 